\title{
Perfis estratégicos de conduta social e ambiental: estudos na indústria têxtil nordestina
}

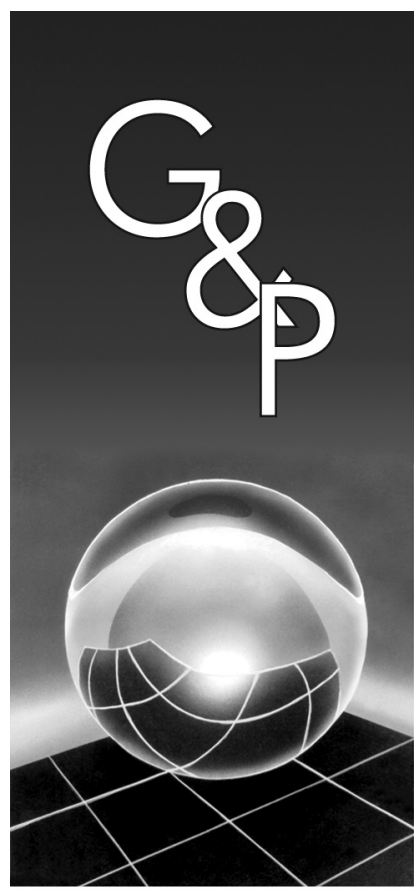

\author{
Mônica Cavalcanti Sá de Abreu \\ José Carlos Lázaro da Silva Filho \\ Bruno Cals de Oliveira \\ Francisco Leite Holanda Júnior
}

\begin{abstract}
Resumo
O trabalho apresenta a avaliação das condutas sociais e ambientais na indústria têxtil nordestina, tendo por base o framework do modelo de avaliação da estratégia tríplice, denominado ECP-triplo (estrutura-conduta-performance-triplo). Com base neste modelo, uma empresa submetida a pressões da estrutura da indústria busca uma performance tríplice (econômica, ambiental e social) e, para tanto, precisa estabelecer condutas claramente sociais e ambientais, além da econômica. A pesquisa na indústria têxtil nordestina foi realizada em empresas representativas do setor e instaladas nos estados do Ceará, Paraíba, Pernambuco e Rio Grande do Norte, através de entrevistas diretas. $O$ estudo analisa as empresas em função do porte e identifica perfis estratégicos de condutas ambientais e sociais, segundo uma escala definida como fraca, intermediária ou forte. Os resultados indicam uma predominância de empresas que adotam condutas fracas. Comparativamente, existe uma maior preocupação com a conduta ambiental que a social. No geral, a medida que aumenta o porte da empresa e o seu acesso aos mercados internacionais, o perfil de conduta social e ambiental tende a um maior nível de responsabilidade.
\end{abstract}

Palavras-chave: Modelo ECP-triplo. Gestão ambiental. Responsabilidade social. Indústria têxtil. Indicadores sociais. Indicadores ambientais.

\section{Introdução}

A indústria têxtil brasileira é caracterizada pela sua heterogeneidade, no que se refere ao porte, à linha de produtos e ao estágio tecnológico e gerencial. No segmento de fiação é expressivo o grau de integração vertical com as demais etapas do processo produtivo. Já no segmento de tecelagem plana, a maior parte das empresas não é integrada. Apenas as maiores empresas que compõem o setor, geralmente produtoras de cama, mesa e banho e fabricantes de tecidos de algodão, como o denim e brins, são integradas em fiação, tecelagem e acabamento. $\mathrm{Na}$ malharia é grande o grau de verticalização, especialmente com a confecção. (GAZETA MERCANTIL, 1999a).

O setor têxtil brasileiro, durante o período de 1974 até 1989, viveu uma situação de relativa proteção do governo, permitindo uma certa acomodação. $\mathrm{O}$ mercado fechado às importações, com uma concorrência pequena, facultava taxas de lucro e não estimulava a competitividade. Por outro lado, em virtude da política cambial do país, o setor tinha dificuldades em sua modernização tecnológica, já que dependia em grande parte das importações de máquinas e equipamentos. No início da década de 1990, com a abertura do mercado brasileiro às importações, $o$ setor têxtil ficou inserido numa situação completamente diferente. Chegaram ao Brasil produtos importados com um preço muito baixo, com os quais as mercadorias nacionais não conseguiam concorrer. A balança comercial do setor passou de superavitária, no início da década, para deficitária a partir de 1995 (GAZETA MERCANTIL, 1999b).

Dentro da estratégia de recuperação da competitividade das empresas ocorreu o deslocamento regional, com a transferência de fábricas para a região nordeste e para o norte de Minas Gerais, em virtude de incentivos fiscais e menores custos com a mão-de-obra. Além dos incentivos fiscais, alguns governos estaduais desenvolveram programas de qualificação e de treinamento de mão-de-obra e promoveram a criação de cooperativas de trabalhadores, que atuavam como subcontratados das indústrias (BANCO DO NORDESTE, 1999). Estados como o Ceará optaram por renúncia fiscal e melhoraram a 
infra-estrutura industrial, com o fornecimento de galpões, energia elétrica, além da modernização de portos e aeroportos (UNE; PROCHNIK, 2000).

Em virtude da escassez de água na região nordeste e da ausência de sistemas adequados de tratamento de efluentes, a implantação da indústria têxtil impõe um elevado risco ambiental à sociedade. Diversos autores (KUNZ; PERALTA-ZAMORA, 2002; BRAILE; CAVALCANTI, 1993) destacam o consumo de água e a geração de efluentes com elevada carga orgânica (agentes engomantes, amido e sabões) e de corantes, como os principais impactos ambientais da indústria têxtil. Em geral, estima-se que aproximadamente 20\% da carga de corantes é perdida nos resíduos de tingimento, o que representa um dos grandes problemas ambientais enfrentados pelo setor têxtil. O COEMA (2004) define as atividades de fiação e tecelagem da indústria têxtil como de médio potencial poluidor degradador (PPD), quando ocorrem sem tingimento, e de alto PPD quando o processo inclui tingimento ou tinturaria.

Com relação ao impacto social, as empresas têxteis demonstram uma inércia inicial para investimentos em projetos sociais, sejam eles internos (na melhoria das condições de trabalho) ou externos (investimentos em educação, saúde ou esportes). Esta inércia decorre do processo de implantação da indústria têxtil no Nordeste, com uma forte participação governamental, através dos incentivos fiscais e da utilização de mão-de-obra de baixo custo (UNE; PROCHNIK, 2000).

Este trabalho, portanto, se propõe a avaliar as condutas sociais e ambientais adotadas por empresas têxteis instaladas no Ceará, Rio Grande do Norte, Paraíba e Pernambuco. A pesquisa foi conduzida em 2006 e analisa as empresas em função do porte, identificando os perfis estratégicos de conduta social e ambiental segundo uma escala definida como fraca, intermediária ou forte.

Além desta introdução e da conclusão, o artigo está estruturado em seções. A seção 2 apresenta o framework dos indicadores do modelo adotado, aprofundando a construção dos indicadores de conduta social e ambiental. A metodologia é discutida na seção 3, já na seção 4 são apresentados os resultados da pesquisa em duas subseções: a primeira contém a conduta social e a segunda a conduta ambiental das empresas têxteis pesquisadas. Por fim, a seção 5 traça o perfil estratégico de conduta social e ambiental das empresas têxteis, tomando por base o porte.

\section{Modelo de avaliação da estratégia tríplice: uma proposta metodológica}

Uma nova forma de comportamento, denominado triple bottom line (TBL), tem emergido em virtude da convergência da dimensão econômica, ambiental e social no planejamento estratégico das empresas. Dentro do contexto da agenda de sustentabilidade, a questão básica do triple bottom line consiste em aproveitar os recursos do setor privado nestes novos imperativos sociais e econômicos, sem comprometer o meio ambiente, e idealmente aumentar os rendimentos econômicos e criar valor para a empresa. Elkington (1999) concebeu o triple bottom line (TBL) para ajudar as empresas a entrelaçarem os três componentes do desenvolvimento sustentável: prosperidade econômica, justiça social e proteção ao meio ambiente, dentro de suas operações principais e essencialmente fazendo o salto da sustentabilidade teórica para a prática.

Atualmente tem sido muito usado o termo "responsabilidade social das empresas", considerando as múltiplas dimensões do papel social da empresa. Para o Instituto Ethos (2000), autor desse modelo, a empresa é socialmente responsável quando vai além da obrigação de respeitar as leis, pagar os impostos e observar as condições de saúde e de segurança dos trabalhadores, buscando construir uma sociedade mais justa. O Instituto desenvolveu os indicadores para avaliar a situação da empresa frente à responsabilidade social, avaliando os benefícios à sociedade, aos parceiros e ao meio ambiente, a realização profissional dos empregados e o retorno para os investidores. Uma análise dos indicadores propostos indica a existência de apenas duas dimensões: a econômica e a social. A dimensão ambiental está inserida na dimensão social.

As empresas vêm então divulgando o balanço social como uma expressão da valorização da responsabilidade social empresarial. A construção dos indicadores sociais abrange os impostos, excluídos os encargos sociais, a contribuição para a sociedade com os investimentos na cidadania e os investimentos em meio ambiente. Através desses balanços sociais observa-se que não existe uma clara distinção entre os limites das dimensões econômica, social e ambiental, bases para o desenvolvimento sustentável.

Neste sentido, Norcia (1996) adverte que dentro da ética ambiental, diferente de outras áreas da ética empresarial, as medidas de performance ambiental devem ser distintas dos indicadores sociais, econômicos e tecnológicos. Por sua vez, Elkington e Trisoglio (1996) afirmam que o conceito de "sustentabilidade" vem tomando parte das principais correntes de discussão política, e as mudanças, entretanto, trazem consigo uma enorme complexidade em termos econômicos, tecnológicos, sociais e ambientais. Os autores consideram que as ferramentas para analisar e modelar as tomadas de decisão no campo e o embasamento teórico dos frameworks estão inadequados ao conceito de sustentabilidade.

Bockermann et al. (2005) argumentam que os estudos foram desenvolvidos como uma "colcha de retalhos", sem 
uma estratégia operacional que permitisse a interligação entre elas. Essa ambigüidade permanece e não pode ser elucidada por uma análise em uma única dimensão (i.e. econômica, ambiental ou social), portanto merece uma abordagem integrada entre as dimensões do desenvolvimento sustentável. O autor argumenta ainda a necessidade de desenvolver modelos estratégicos para a tomada de decisão, baseados não apenas na performance ambiental, mas também nas necessidades das partes interessadas e nos impactos econômicos da escolha estratégica. Os modelos devem ser capazes de avaliar as estratégias e identificar os efeitos sinérgicos e os trade-offs.

Abreu (2001), diante da necessidade de avaliar a estratégia utilizada pela empresa, não somente na dimensão econômica, mas também social e ambiental, ampliou e reespecificou o paradigma SCP (structureconduct-performance) formulado por Mason (1930 apud SCHERER; ROSS, 1990, p. 4). O paradigma SCP dita que a performance da empresa é o reflexo de suas práticas competitivas, estas decorrentes de padrões de conduta e dependentes da estrutura de mercado na qual a empresa está inserida. Adotando as mesmas premissas, Abreu (2001) formulou o modelo ECP-triplo (estrutura-conduta-performance).

Este modelo possibilita uma análise da estrutura da indústria em termos de pressões por responsabilidade social e ambiental, além das questões relacionadas à oferta e à demanda. $\mathrm{O}$ posicionamento estratégico da empresa dentro da estrutura da indústria, e conseqüentemente, sua performance tríplice (econômica, ambiental e social), será definido por suas condutas econômica, ambiental e social, traduzidas no modelo de gestão adotado pela organização.

O paradigma SCP estabelece que a estrutura da indústria é determinante para a definição das vantagens competitivas (BAIN, 1956). Entretanto, as pesquisas foram conduzidas com um foco nas características da estrutura da indústria e pouca atenção foi dada aos recursos da firma, às competências centrais e aos processos de tomada de decisão (McWILLIAMS; SMART, 1993). O Modelo ECP-triplo analisa a competição como um processo e, portanto, elimina esse problema do paradigma SCP. Um processo competitivo pode ocorrer em várias estruturas da indústria, desde altamente concentradas até desconcentradas (DEMSETZ, 1973). Isto implica que as oportunidades para as vantagens competitivas são possíveis em todas as estruturas de mercado (RUMELT, 1991).

OModeloPSR (pressão-estado-resposta), desenvolvido pela OECD (Organisation for Economic Co-operation and Development), também foi utilizado para construir os conceitos de pressão da estrutura da indústria, de conduta e de performance ambiental. O modelo PSR adota o conceito de causalidade e considera que as atividades humanas exercem pressões no meio ambiente, que afetam a qualidade e a quantidade dos recursos naturais (estado) e a sociedade responde a essas mudanças, através de políticas públicas e setoriais e de mudanças no seu comportamento (OECD, 1998). Rye e Celius (1997) aplicaram o modelo PSR na indústria de óleo e gás e propuseram uma adaptação no framework. As pressões significaram a integração entre as preocupações ambientais e as demandas das partes interessadas, os indicadores de resposta representaram a integração entre as preocupações ambientais e as ações das firmas, e os indicadores de estado avaliaram a performance ambiental da empresa.

O modelo conceitual tridimensional de performance corporativa, desenvolvido por Carroll (1979), foi utilizado no desenvolvimento dos indicadores de conduta e performance social do modelo ECP-Triplo. O modelo de Carroll admite a existência de três dimensões: questões sociais, categorias de responsabilidade social e filosofia da resposta social. No caso das questões sociais (i.e. discriminação, consumismo, meio ambiente, segurança do produto, segurança ocupacional e partes interessadas) é importante ressaltar, que essas questões mudam e são diferentes conforme a indústria, levando a empresa à definição de respostas diferenciadas. O autor admite a existência de comportamentos sociais na empresa, que vão desde a responsabilidade econômica, seguida da responsabilidade legal e ética, até à responsabilidade discricionária, com a implantação de projetos sociais para as partes interessadas internas e externas.

O Modelo ECP-triplo assume que as empresas operam em um ambiente de cooperação e rivalidade. O framework dos indicadores do modelo ECP-triplo é apresentado no Quadro 1, contemplando os choques, a estrutura, a conduta e a performance, nas suas dimensões econômica, ambiental e social. Na concepção do Modelo ECP-Triplo foi adotada a existência de feedbacks internos, que de acordo com Porter (1980) conferem um dinamismo ao paradigma SCP. Scherer e Ross (1990) reconhecem também que nem todas as influências derivam das condições básicas, definidas por elementos de oferta e demanda, fluindo da estrutura de mercado para a performance, sendo igualmente significativos os efeitos dos feedbacks.

A estrutura de mercado em que a organização se encontra é afetada por choques externos, fazendo com que novas condutas sejam necessárias. Os choques são basicamente provenientes da ação governamental, das inovações tecnológicas e das mudanças no comportamento social com a crescente sensibilização para as questões sociais e ambientais. Assim, os indicadores de performance associados às condutas devem ser compatíveis com a realidade das estruturas de mercado em constante mudança.

Os indicadores de estrutura de mercado do modelo ECP-triplo abrangem, além dos fatores já abordados 
Quadro 1. Framework do modelo ECP-triplo (adaptado de ABREU, 2001).

\begin{tabular}{|c|c|c|c|}
\hline $\begin{array}{l}\text { Choques } \\
\text { externos }\end{array}$ & $\begin{array}{l}\text { Ação governamental } \\
\text { política/regulação }\end{array}$ & Inovações tecnológicas & Mudanças no comportamento social \\
\hline $\begin{array}{l}\text { Estrutura da } \\
\text { indústria }\end{array}$ & $\begin{array}{l}\text { Economia da demanda } \\
\text { Disponibilidade de substitutos; } \\
\text { Diferenciação de produtos; } \\
\text { Taxa de crescimento; e } \\
\text { Volatilidade/ciclicidade. } \\
\text { Economia da oferta } \\
\text { Concentração de produtores; } \\
\text { Competição de importadores; } \\
\text { Diversidade de produtores; } \\
\text { Estrutura de custos fixos/vari- } \\
\text { áveis; } \\
\text { Utilização da capacidade; } \\
\text { Oportunidades tecnológicas; } \\
\text { Forma da curva de oferta; e } \\
\text { Barreiras de entrada e saída. }\end{array}$ & $\begin{array}{l}\text { Economia da cadeia industrial } \\
\text { Poder de barganha dos fornecedores; } \\
\text { Poder de barganha dos clientes; } \\
\text { Falhas de informações no mercado; e } \\
\text { Falhas na integração vertical. }\end{array}$ & $\begin{array}{l}\text { Características socioambientais } \\
\text { Riscos ambientais; } \\
\text { Demanda das partes interessadas; e } \\
\text { Legislação e fiscalização (ambiental, } \\
\text { trabalhista e previdenciária). }\end{array}$ \\
\hline $\begin{array}{l}\text { Conduta } \\
\text { tríplice }\end{array}$ & $\begin{array}{l}\text { Econômico } \\
\text { Administração } \\
\text { Mudança de capacidade, } \\
\text { integração vertical, política } \\
\text { da qualidade, estrutura orga- } \\
\text { nizacional, planejamento dos } \\
\text { objetivos e metas, alocação } \\
\text { de recursos (humano, físico } \\
\text { e financeiro), treinamento e } \\
\text { desenvolvimento profissional, } \\
\text { acompanhamento da legisla- } \\
\text { ção tributária. } \\
\text { Pesquisa e desenvolvimento } \\
\text { Novos produtos e processos. } \\
\text { Produção e operação } \\
\text { Controle de custos, logística } \\
\text { e distribuição, auditoria, } \\
\text { exigências contratuais aos } \\
\text { fornecedores de produtos e } \\
\text { serviços, controles e padrões } \\
\text { operacionais, monitoramento } \\
\text { e controle da qualidade. } \\
\text { Marketing } \\
\text { Precificação, necessidades } \\
\text { do mercado, propaganda e } \\
\text { promoção. }\end{array}$ & $\begin{array}{l}\text { Ambiental } \\
\text { Administração } \\
\text { Política ambiental, estrutura organiza- } \\
\text { cional, exigências legais e outras exi- } \\
\text { gências, objetivos, metas e programas } \\
\text { ambientais, alocação de recursos em } \\
\text { projetos ambientais (humano, físico e } \\
\text { financeiro), desenvolvimento e educa- } \\
\text { ção ambiental. } \\
\text { Pesquisa e desenvolvimento } \\
\text { Selo verde e tecnologias de prevenção } \\
\text { da poluição. } \\
\text { Produção e operação } \\
\text { Aspectos ambientais, controles ope- } \\
\text { racionais, exigências ambientais aos } \\
\text { fornecedores de produtos e serviços, } \\
\text { auditoria ambiental, monitoramento e } \\
\text { medição ambiental e plano de atendi- } \\
\text { mento a situações de emergência. } \\
\text { Marketing } \\
\text { Comunicação com as partes interessa- } \\
\text { das e relatórios ambientais. }\end{array}$ & $\begin{array}{l}\text { Social } \\
\text { Administração } \\
\text { Política de responsabilidade social, } \\
\text { códigos de ética e balanço social, } \\
\text { exigências legais e outras exigências, } \\
\text { objetivos, metas e programas sociais, } \\
\text { alocação de recursos em projetos } \\
\text { sociais internos e externos (humano, } \\
\text { físico e financeiro), programas de vo- } \\
\text { luntariado, benefícios legais e extras. } \\
\text { Pesquisa e desenvolvimento } \\
\text { Projetos sociais, tecnologias de } \\
\text { prevenção e controle dos riscos } \\
\text { ocupacionais. } \\
\text { Produção e operação } \\
\text { Riscos e perigos, controles operacio- } \\
\text { nais, exigências de responsabilidade } \\
\text { social aos fornecedores de produtos } \\
\text { e serviços, auditorias, monitoria e } \\
\text { medição de saúde e segurança no } \\
\text { trabalho. } \\
\text { Marketing } \\
\text { Relacionamento com as partes inte- } \\
\text { ressadas. }\end{array}$ \\
\hline $\begin{array}{l}\text { Performance } \\
\text { tríplice }\end{array}$ & $\begin{array}{l}\text { Econômico } \\
\text { Rentabilidade; } \\
\text { Criação de valor; e } \\
\text { Eficiência (na alocação de } \\
\text { recursos e na produção) Parti- } \\
\text { cipação no mercado }\end{array}$ & $\begin{array}{l}\text { Ambiental } \\
\text { Ar } \\
\text { Concentração de gases do efeito estufa, } \\
\text { substâncias destruidoras da camada de } \\
\text { ozônio, chuva ácida e ruído. } \\
\text { Água } \\
\text { Geração de efluentes, eutrofização, } \\
\text { acidificação e contaminação tóxica. } \\
\text { Solo } \\
\text { Geração de resíduos sólidos, contami- } \\
\text { nação tóxica, acidificação. } \\
\text { Recursos Naturais } \\
\text { Intensidade do uso de recursos hídri- } \\
\text { cos, energéticos, florestais e marinhos. } \\
\text { Biodiversidade } \\
\text { Alteração do habitat, mudança do uso } \\
\text { do solo e perda de biodiversidade. }\end{array}$ & $\begin{array}{l}\text { Social } \\
\text { Bem-estar } \\
\text { Geração de emprego; } \\
\text { Ambiência organizacional; } \\
\text { Cumprimento das exigências éticas e } \\
\text { legais; e } \\
\text { Segurança e saúde no trabalho (da } \\
\text { força de trabalho e da comunidade no } \\
\text { entorno). } \\
\text { Imagem } \\
\text { Exposições espontâneas na mídia; e } \\
\text { Envolvimento e acompanhamento de } \\
\text { projetos sociais. }\end{array}$ \\
\hline
\end{tabular}


no paradigma SCP, as características socioambientais compostas da: legislação e fiscalização ambiental, trabalhista, previdenciária e tributária; exigências das partes interessadas e os riscos ambientais decorrentes do processo produtivo. As pressões exercidas por estas características variam de acordo com a estrutura da indústria.

Os indicadores de conduta abrangem as dimensões econômica, ambiental e social, em todas as suas funções gerenciais, definidas como administração; pesquisa e desenvolvimento; produção e operação; e marketing. Na definição dos indicadores de conduta ambiental foram considerados os requisitos da ISO 14001, que estabelece as especificações e diretrizes para a implantação e uso do sistema de gestão ambiental (SGA). Exemplos de indicadores de conduta ambiental são: montante dos investimentos ambientais; número de multas e notificações recebidas; resposta às situações de emergência; auditorias conduzidas; alcance dos objetivos e metas ambientais; política ambiental; programas de educação ambiental implementados; exigências ambientais aos fornecedores; e medidas de controle operacional e monitoramento da poluição.

Abreu et al. (2002) propuseram que, dependendo do posicionamento frente aos indicadores de conduta ambiental, as organizações podem ser classificadas com um perfil de conduta ambiental forte, intermediária ou fraca. As empresas com uma conduta ambiental forte fazem uma avaliação quantitativa da sua performance. Entretanto, as empresas com uma conduta ambiental intermediária estão iniciando o processo de quantificação da performance ambiental. Por outro lado, as empresas com uma conduta ambiental fraca não praticam essas medições.

Os autores demonstraram que as empresas que apresentam conduta ambiental forte possuem uma política ambiental com objetivos e metas, programas de gestão ambiental com recursos, meios e prazos definidos. Conhecem e acompanham a legislação ambiental, definem indicadores de performance ambiental, desenvolvem programas de educação ambiental e coleta seletiva, e têm sistemas de gestão ambiental certificados pela ISO 14001. As empresas avaliam o impacto ambiental de suas atividades e produtos; empregam tecnologias avançadas para tratamento das emissões/resíduos/efluentes e possuem controles operacionais e planos de respostas às emergências; possuem canais de comunicação; e elaboram relatórios de desempenho ambiental. A importância da questão ambiental para a empresa está vinculada ao compromisso com o desenvolvimento sustentável e com a imagem da empresa.

A conduta ambiental intermediária é identificada em empresas que estão em fase de implantação de um sistema de gestão ambiental. A política ambiental está em fase de elaboração e estão levantando os aspectos ambientais significativos. Iniciaram a definição de padrões e controles ambientais. Paralelamente, investem em programas de educação ambiental e na aquisição de equipamentos para reduzir o consumo de recursos naturais (água e energia). Verifica-se uma preocupação com a imagem e com o alcance de novos mercados.

As empresas que possuem uma conduta ambiental fraca não possuem uma política ambiental e não definiram um responsável para tratar das questões ambientais. Também não possuem padrões ambientais e não têm planos de implantar um sistema de gestão ambiental. A dotação de recursos financeiros não envolve projetos ambientais, programas de educação ambiental ou de coleta seletiva. Os controles operacionais estão limitados ao estrito cumprimento dos requisitos legais. Enfim, enxergam as questões ambientais como um custo, sem a promoção de vantagem competitiva.

Seguindo a linha de raciocínio da dimensão ambiental, os indicadores de conduta social foram considerados os requisitos da social accountability SA 8000 (Responsabilidade Social SA 8000:2001), que é uma norma mundial verificável para administrar, auditar e certificar a colaboração com as questões envolvendo o ambiente de trabalho. Foram também observados os requisitos definidos pelo Instituto Ethos (2000) para definir as partes interessadas internas e externas. As partes interessadas internas envolvem a força de trabalho da empresa, composta de empregados próprios e terceirizados. Por outro lado, as partes interessadas externas abrangem a comunidade no entorno da empresa, a sociedade em geral, as organizações governamentais e as não governamentais, os clientes e os fornecedores.

Exemplos de indicadores de conduta social são: montante dos investimentos nos projetos sociais; número de multas e notificações trabalhistas e previdenciárias; número de auditorias sociais conduzidas; alcance dos objetivos e metas sociais; política de responsabilidade social; programas de voluntariado implementados; exigências sociais aos fornecedores, como o combate ao trabalho infantil e a discriminação; além das medidas de controle e monitoramento da segurança e saúde no trabalho.

A empresa pode ser classificada como possuidora de uma conduta social forte, intermediária ou fraca. A conduta social forte caracteriza-se pelo desenvolvimento de projetos sociais internos, que vão além da legislação e de projetos sociais externos. Tais projetos são desenvolvidos através de uma fundação ou em parceria com organizações não governamentais, têm continuidade e atendem, em geral, a problemas críticos da comunidade onde a organização esta inserida. Os projetos possuem uma visão no tripé de sustentabilidade. Os investimentos são definidos para atender os objetivos e as metas sociais 
da empresa. As empresas possuem programa de desenvolvimento profissional formalizado e estão implantando ou certificando seus sistemas de gestão de segurança e saúde no trabalho e/ou de responsabilidade social. Fazem exigências sociais contratuais aos fornecedores e avaliam os riscos e perigos de saúde e segurança no trabalho para os funcionários próprios e contratados. Estas empresas antecipam as preocupações sociais de seus clientes e já percebem vantagens competitivas associadas com a melhoria da imagem, da produtividade e da ambiência organizacional.

Uma empresa possuidora de uma conduta social intermediária realiza alguns projetos que estão além das obrigações legais. A empresa realiza algumas ações isoladas ou situacionais que beneficiam de alguma forma seus stakeholders interno e externo, porém sem um planejamento de médio e longo prazo. Possuem um programa de desenvolvimento profissional informal, estão no estágio inicial de um sistema de gestão de saúde e segurança no trabalho ou de responsabilidade social e não fazem exigências sociais contratuais aos seus fornecedores. Não completaram a avaliação dos riscos e perigos de segurança e saúde no trabalho.

Uma conduta social fraca é caracterizada pela empresa que tem suas ações sociais limitadas ao cumprimento da legislação vigente. Isso implica em ações sociais voltadas apenas para o público interno. Os investimentos em projetos sociais são definidos apenas para atender a legislação trabalhista. As empresas não possuem um programa de desenvolvimento profissional, não possuem sistemas de gestão de saúde e segurança no trabalho ou de responsabilidade social, também não fazem exigências sociais aos seus fornecedores e não avaliam os riscos e perigos de saúde e segurança no trabalho. As empresas desconhecem a preocupação social dos concorrentes, ou seja, não identificam vantagens competitivas com a conduta social.

Concluindo o framework do modelo ECP-triplo, os indicadores de performance nas dimensões social, econômica e ambiental foram divididos em compartimentos. No modelo ECP-triplo, os indicadores de performance ambiental estão divididos em compartimentos: ar, água, solo, recursos naturais e biodiversidade, cada um largamente independente do outro, em termos de medidas e controle das descargas ou efeitos. Os indicadores de performance social foram divididos em dois compartimentos: bem-estar e imagem.

Assim, considerando os fundamentos estabelecidos no modelo ECP-triplo, a pesquisa que o artigo relata testa a hipótese de que existem perfis característicos de conduta social e ambiental, e que as empresas têxteis adotam perfis distintos em função do porte.

\section{Metodologia}

O primeiro passo dessa pesquisa de estudos setoriais envolveu o aprofundamento dos indicadores do modelo ECP-Triplo. Concluído o framework do modelo, ocorreu o desenvolvimento de um instrumento de coleta de dados, a aplicação das entrevistas piloto, seguida da definição da amostra e do levantamento dos dados, com entrevistas diretas aos dirigentes das empresas selecionadas.

O instrumento de coleta de dados foi elaborado para identificar a aderência das respostas dos entrevistados aos indicadores de estrutura, conduta e performance econômica, ambiental e social, propostos pelo modelo ECP-Triplo. As perguntas foram elaboradas buscando identificar se a empresa adotava os indicadores do modelo, como os adotava, e qual o impacto da conduta no desempenho da empresa. O instrumento desenvolvido separa cartesianamente as condutas e performances em ambientais e sociais (dois pés do "tripé", completado pela econômica - também levantada). A estrutura das questões ambientais segue a metodologia desenvolvida em pesquisas anteriores (ABREU, 2001), a literatura a partir de Elkington (1998) e as diretrizes do global report initiative (GRI), este opta por considerar separadamente os indicadores econômicos, ambientais e sociais. Paralelamente, as questões sociais foram definidas conforme literatura proposta por Carrol (1979), combinando com as questões do Balanço Social do IBASE, do Pacto Global e do Instituto Ethos (INSTITUTO ETHOS, 2000).

O questionário com cerca de 90 perguntas foi dividido em "dados da empresa/estrutura do mercado", "conduta econômica", "conduta ambiental" e conduta social conforme as funções gerenciais: administração; pesquisa e desenvolvimento; produção e operação; e marketing - além da "Performance Econômica", "Performance Ambiental" e "Performance Social". Poucas perguntas abertas entrelaçavam-se com um questionário estruturado, contendo perguntas de intensidade com uma escala Likert de cinco pontos - muito pouco (1), pouco (2), médio (3), muito (4) e muitíssimo (5) - e perguntas de freqüência (múltipla escolha e sim ou não).

A pesquisa foi realizada em 16 empresas, das quais oito localizadas no estado do Ceará, uma na Paraíba, quatro em Pernambuco e três no Rio Grande do Norte. Do total de empresas entrevistadas, três são de pequeno porte, seis de médio e sete de grande porte. O pólo têxtil do Nordeste é caracterizado por empresas de fiação, tecelagem e malharia, de pequeno, médio e grande porte, que utilizam o algodão como matéria-prima.

A entrevista piloto ocorreu em três empresas têxteis do Ceará e possibilitou o ajuste do instrumento de coleta de dados e a compreensão dos elementos que compõem a estrutura de mercado, a conduta e as performances econômica, ambiental e social da indústria têxtil. 
A escolha dos casos a serem estudados foi intencional e não probabilística. Depois de identificado o universo da indústria têxtil nordestina, buscou-se o contato com as empresas (telefone, fax e/ou correio eletrônico) e com os sindicatos patronais estaduais. A amostra final representa mais de $50 \%$ da produção têxtil nordestina (em toneladas), cumprindo o critério de representatividade de porte e da posição na cadeia produtiva têxtil (fiação, tecelagem e malharia). Para o porte utilizou-se a classificação do Instituto Brasileiro de Geografia e Estatística - IBGE, na qual são caracterizadas como pequenas indústrias aquelas que têm entre 1 e 100 funcionários, as médias têm entre 101 e 500, e as grandes são as que têm mais de 500 funcionários.

Os dados foram tabulados e analisados. Os indicadores de conduta social e ambiental foram analisados para cada função gerencial, visando identificar se a conduta adotada por cada empresa pesquisada era forte, intermediária ou fraca.

\section{Análise e discussão dos resultados}

\subsection{Condutas sociais das empresas têxteis}

A pesquisa revelou que 15 empresas não haviam elaborado um código de ética, e uma empresa não respondeu esta questão. Por outro lado, a metade das empresas entrevistadas participa de projetos sociais. Dentre os responsáveis pelos projetos sociais, três são diretores, três são gerentes e um é coordenador, havendo uma empresa cujos projetos sociais são da responsabilidade da presidência. O restante das empresas que afirmaram não haver responsável por projetos sociais, quatro são de médio porte, duas de pequeno e duas de grande porte.

Com relação aos setores em que atuam os responsáveis pelos projetos sociais, seis estão alocados no setor de recursos humanos e um na administração geral. Em uma empresa essa responsabilidade se encontra difusa em diferentes setores. A definição de um responsável gerencial pelos projetos sociais exige um porte médio ou grande, quando a empresa já possui um setor de recursos humanos.

Independente da participação em projetos sociais, a conduta social requer o conhecimento da legislação trabalhista e previdenciária. Analisando os aspectos jurídicos, verificou-se que todas as empresas afirmam conhecer esta legislação, em virtude da regulamentação trabalhista e tributária que está mais permeada na sociedade e controlada pelo estado.

$\mathrm{Na}$ parte financeira foram analisados os investimentos sociais. Das 14 empresas que responderam a essa questão, apenas uma empresa (grande porte) aloca recursos na faixa entre $\mathrm{R} \$ 501$ mil e $\mathrm{R} \$ 1$ milhão, outra empresa (também de grande porte) aloca entre $\mathrm{R} \$ 101 \mathrm{mil}$ e R \$ 500 mil, as outras doze afirmam gastar menos de $\mathrm{R} \$ 100$ mil anuais. Esses valores representam menos de $1 \%$ do faturamento para onze delas (inclusive a que mais investe). Uma empresa pequena, uma média e outra de grande porte indicam que esses "menos de $\mathrm{R} \$ 100 \mathrm{mil}$ reais" significam entre 1 e $2 \%$ do faturamento.

Através de uma questão de freqüência/múltipla escolha, 12 empresas responderam as motivações para os investimentos na área social. Sete empresas afirmaram o atendimento aos requisitos legais. As empresas ainda relataram a existência de projetos propostos por seus funcionários (6) e outros gerados para atender às metas da empresa (6). Quanto aos motivos relacionados com uma conduta social mais pró-ativa não é possível identificar uma relação com o porte.

No que tange à área de recursos humanos, sabe-se que a concessão de benefícios extras é uma conduta social (interna) que diferencia as empresas além de sua função básica de gerar emprego e cumprir as leis. A identificação dos benefícios oferecidos aos empregados (medidos através de uma questão de frequiência/múltipla escolha) foi respondida pelas treze entrevistadas (Tabela 1). Alguns benefícios como o $14^{\circ}$ salário, a concessão de crédito e a participação de resultados apresentam-se vinculados ao porte, característicos de grandes e médias empresas.

A Tabela 2 mostra as áreas de atuação dos projetos sociais nas empresas pesquisadas. Observa-se que seis empresas expõem que o impacto social da sua atividade é a "geração de emprego e renda". As empresas têm maior interesse em investimentos nas áreas de educação e saúde. Entretanto, considerando que duas empresas respondentes são de médio porte, uma de grande e outra de pequeno porte, não é possível inferir alguma diferenciação por porte.

Também foi perguntado sobre os benefícios operacionais e organizacionais oriundos do desenvolvimento de projetos sociais (Tabela 3). Este item teve uma maior freqüência de avaliação. Há uma forte valoração dos benefícios para a imagem nas grandes empresas, seguida

Tabela 1. Benefícios extras concedidos aos funcionários.

\begin{tabular}{lcccc}
\hline & & \multicolumn{3}{c}{ Freqüências por porte } \\
\cline { 3 - 5 } \multicolumn{1}{c}{ Benefícios } & nr & Pequena & Média & Grande \\
\hline Espaço de lazer & 9 & 2 & 3 & 4 \\
Plano de saúde & 7 & 1 & 3 & 3 \\
Prêmios/bônus & 7 & 2 & 3 & 2 \\
Concessão de crédito & 6 & 2 & 0 & 4 \\
Participação nos & 6 & 0 & 2 & 4 \\
resultados & & & & \\
\hline
\end{tabular}

nr: número de respondentes. 
Tabela 2. Áreas de atuação dos projetos sociais.

\begin{tabular}{|c|c|c|c|c|c|c|c|c|c|}
\hline \multirow[b]{3}{*}{ Áreas } & \multicolumn{3}{|c|}{ Avaliação geral } & \multicolumn{6}{|c|}{ Avaliação por porte } \\
\hline & \multirow[b]{2}{*}{ nr } & \multirow[b]{2}{*}{$\mu$} & \multirow[b]{2}{*}{ Desvio padrão $\sigma$} & \multicolumn{2}{|c|}{ Pequena } & \multicolumn{2}{|c|}{ Média } & \multicolumn{2}{|c|}{ Grande } \\
\hline & & & & nr & $\mu$ & nr & $\mu$ & $\mathbf{n r}$ & $\mu$ \\
\hline Educação & 4 & 3,5 & 1,73 & 1 & 4 & 2 & 4,5 & 1 & 1,0 \\
\hline Saúde & 4 & 3,3 & 1,50 & 1 & 4 & 2 & 4,0 & 1 & 1,0 \\
\hline Geração de emprego e renda & 6 & 3,0 & 1,67 & 1 & 1 & 3 & 4,0 & 2 & 2,5 \\
\hline Esporte e lazer & 4 & 2,8 & 1,25 & 1 & 3 & 2 & 3,5 & 1 & 1,0 \\
\hline Segurança & 4 & 2,8 & 1,25 & 1 & 3 & 2 & 3,5 & 1 & 1,0 \\
\hline Inclusão digital & 4 & 2,3 & 1,89 & 1 & 1 & 2 & 3,5 & 1 & 1,0 \\
\hline Infra-estrutura da comunidade & 5 & 2,2 & 1,30 & 1 & 2 & 2 & 2,0 & 2 & 2,5 \\
\hline
\end{tabular}

Escala de 1 a 5 ( 1 = muito pouco; $2=$ pouco; 3 = médio; 4 = muito; e $5=$ muitíssimo $)$ e nr: número de respondentes $/ \mu=$ média.

Tabela 3. Benefícios oriundos dos projetos sociais para a empresa.

\begin{tabular}{|c|c|c|c|c|c|c|c|c|c|}
\hline \multirow[b]{3}{*}{ Benefícios } & \multicolumn{3}{|c|}{ Avaliação geral } & \multicolumn{6}{|c|}{ Avaliação por porte } \\
\hline & \multirow[b]{2}{*}{ nr } & \multirow[b]{2}{*}{$\mu$} & \multirow[b]{2}{*}{ Desvio padrão $\sigma$} & \multicolumn{2}{|c|}{ Pequena } & \multicolumn{2}{|c|}{ Média } & \multicolumn{2}{|c|}{ Grande } \\
\hline & & & & $\mathrm{nr}$ & $\mu$ & $\mathrm{nr}$ & $\mu$ & $\mathbf{n r}$ & $\mu$ \\
\hline Aumento de produtividade & 10 & 4,1 & 1,20 & 1 & 4,0 & 3 & 4,7 & 6 & 3,8 \\
\hline $\begin{array}{l}\text { Melhoria do ambiente organiza- } \\
\text { cional }\end{array}$ & 10 & 3,8 & 1,14 & 1 & 3,0 & 3 & 4,3 & 6 & 3,7 \\
\hline Melhoria da imagem & 10 & 4,4 & 0,52 & 1 & 4,0 & 3 & 4,3 & 6 & 4,5 \\
\hline Isenção fiscal & 6 & 1,7 & 0,82 & 1 & 1,0 & 2 & 2,5 & 3 & 1,3 \\
\hline Redução de reclamações & 7 & 3,0 & 1,73 & 1 & 1,0 & 2 & 3,5 & 4 & 3,3 \\
\hline $\begin{array}{l}\text { Diminuição de acidentes e doen- } \\
\text { ças no trabalho }\end{array}$ & 9 & 3,3 & 1,32 & 1 & 3,0 & 2 & 4,0 & 6 & 3,2 \\
\hline Redução de multas & 6 & 1,7 & 1,21 & 1 & 1,0 & 1 & 2,0 & 4 & 1,8 \\
\hline Novos negócios & 7 & 1,9 & 1,21 & 1 & 1,0 & 2 & 2,5 & 4 & 1,8 \\
\hline
\end{tabular}

Escala de 1 a 5 ( 1 = muito pouco; 2 = pouco; 3 = médio; 4 = muito; e $5=$ muitíssimo); e nr: número de respondentes $/ \mu=$ média.

por melhoria na produtividade e na ambiência organizacional nas médias empresas.

Foram também consideradas as informações oriundas das questões abertas. Observa-se que as empresas interpretam distintamente o significado de conduta social. Por exemplo, consideram a existência de um campo de futebol na empresa aberto à comunidade ou mesmo a distribuição de cestas básicas (exigência legal) como uma atuação socialmente responsável. Esta dificuldade decorre da ausência de indicadores de performance que mensurem o impacto de uma conduta social. Paralelamente, os stakeholders da indústria têxtil nordestina exercem uma baixa pressão por uma mudança de comportamento das empresas.

Analisando a conduta social do setor têxtil, observa-se também uma diversidade nos perfis adotados, concentrando-se nos perfis intermediários e fracos (Tabela 4). A pesquisa revela que apenas duas empresas adotam os perfis de conduta forte, quatro possuem uma conduta intermediária e dez revelaram uma conduta fraca.
Tabela 4. Avaliação do perfil de conduta social.

\begin{tabular}{lrccc}
\hline & & \multicolumn{3}{c}{ Freqüências por porte } \\
\cline { 3 - 5 } Perfis de conduta social & nr & Pequena & Média & Grande \\
\hline Conduta fraca & 10 & 2 & 5 & 3 \\
Conduta intermediária & 4 & 1 & 1 & 2 \\
Conduta forte & 2 & - & - & 2 \\
\hline
\end{tabular}

nr: número de respondentes.

Fazendo uma análise por porte, observa-se que duas pequenas empresas adotam uma conduta fraca e apenas uma empresa possui uma conduta intermediária. As empresas de médio porte concentram-se nos perfis de conduta social fraca (5 empresas) e intermediária (1 empresa). A conduta social forte só se revela em duas grandes empresas. Entretanto, duas grandes empresas adotam a conduta social intermediária e outras três a conduta fraca. Portanto, o porte não é uma condição que obriga uma conduta social nas empresas têxteis pesquisadas, contudo, é uma condição necessária para que ocorra uma conduta social mais responsável. 
4.2 Condutas ambientais nas empresas têxteis

A pesquisa revela que apenas quatro empresas (das 16 entrevistadas) possuem política ambiental formalizada, sendo uma de médio e três de grande porte. Oito empresas possuem responsáveis para o tratamento das questões ambientais, em quatro empresas eles estão alocados no setor de meio ambiente (2) ou no setor de manutenção/utilidade (2). Outras quatro empresas alocaram os responsáveis em setores diversos. Oito empresas entrevistadas não possuem este responsável, das quais três são de pequeno porte, quatro de médio e uma de grande porte. Estes resultados permitem inferir uma relação entre o porte e a existência de um responsável na estrutura organizacional para tratar das questões ambientais.

A pesquisa mostra a predominância da responsabilidade ambiental executada a cargo da diretoria (cinco empresas das doze respondentes) ou da gerência (também cinco casos), restando uma empresa, na qual as questões ambientais são tratadas pela presidência. Uma única empresa estabeleceu uma área de coordenação.

No aspecto jurídico avaliou-se o grau de conhecimento sobre a legislação ambiental (Tabela 5) pertinente à empresa e ao setor. Observa-se uma elevada compre- ensão dos requisitos legais aplicáveis, percebendo-se um crescimento com o porte.

Com relação à área financeira, foram identificados investimentos em 15 empresas para atender a legislação ambiental (Tabela 6). A avaliação geral indica uma tendência a valorizar os itens: adequação à legislação; melhoria da qualidade das emissões; redução de desperdícios; e redução de multas, os quais foram avaliados em importância acima de 3,5. Nota-se que as empresas de grande porte percebem os impactos dos investimentos ambientais para a competitividade, pontuando-os na escala Likert acima da média $(>3)$.

As empresas de pequeno e médio porte enfatizam a "adequação à legislação" e "a qualidade das emissões", focando as pequenas ainda a "redução de multas" e a "redução dos desperdícios". O impacto com maior divergência pelo porte é o "aumento de produtividade", percebido somente pelas grandes empresas. A "realização de novos negócios" possui uma baixa importância para as pequenas empresas e vai aumentando conforme o porte.

Foram avaliadas as áreas nas quais as empresas investem para atender à legislação. Cinco empresas (das quinze respondentes) afirmaram que não investem em nenhuma área específica, ficando a cargo do órgão de fiscalização definir as prioridades. As dez empresas

Tabela 5. Conhecimento da legislação ambiental aplicável.

\begin{tabular}{|c|c|c|c|c|c|}
\hline \multicolumn{3}{|c|}{ Avaliação geral } & \multicolumn{3}{|c|}{ Avaliação por porte } \\
\hline & & & Pequena & Média & Grande \\
\hline Indicador & $\mathrm{nr}=16$ & Desvio padrão $\sigma$ & $\mathrm{nr}=\mathbf{3}$ & $\mathrm{nr}=6$ & $\mathrm{nr}=7$ \\
\hline Grau de conhecimento da legislação ambiental & 4,1 & 0,91 & 3,3 & 4,2 & 4,3 \\
\hline
\end{tabular}

Escala de 1 a 5 ( 1 = muito pouco; 2 = pouco; 3 = médio; 4 = muito; e 5 = muitíssimo); e nr: número de respondentes.

Tabela 6. Impacto percebido dos investimentos ambientais na competitividade.

\begin{tabular}{|c|c|c|c|c|c|c|c|c|c|}
\hline \multirow[b]{3}{*}{ Indicadores } & \multicolumn{3}{|c|}{ Avaliação geral } & \multicolumn{6}{|c|}{ Avaliação por porte } \\
\hline & \multirow[b]{2}{*}{ nr } & \multirow[b]{2}{*}{$\mu$} & \multirow[b]{2}{*}{ Desvio padrão $\sigma$} & \multicolumn{2}{|c|}{ Pequena } & \multicolumn{2}{|c|}{ Média } & \multicolumn{2}{|c|}{ Grande } \\
\hline & & & & nr & $\mu$ & $\mathbf{n r}$ & $\mu$ & $\mathbf{n r}$ & $\mu$ \\
\hline Realização de novos negócios & 9 & 2,2 & 1,48 & 2 & 1,5 & 4 & 1,8 & 3 & 3,3 \\
\hline Qualidade e quantidade dos resíduos sólidos & 9 & 2,9 & 1,27 & 2 & 2,0 & 4 & 2,8 & 3 & 3,7 \\
\hline Redução de custos & 8 & 3,0 & 1,31 & 2 & 2,0 & 3 & 3,0 & 3 & 3,7 \\
\hline Ambiência organizacional & 7 & 3,0 & 1,29 & 2 & 3,0 & 2 & 3,0 & 3 & 3,0 \\
\hline Qualidade e quantidade de emissões gasosas & 6 & 3,2 & 1,17 & 2 & 3,5 & 3 & 3,0 & 1 & 3,0 \\
\hline Aumento de produtividade & 9 & 3,2 & 1,20 & 2 & 2,5 & 4 & 2,8 & 3 & 4,3 \\
\hline Imagem & 9 & 3,2 & 1,30 & 2 & 3,5 & 4 & 2,8 & 3 & 3,7 \\
\hline Redução de reclamações & 8 & 3,4 & 1,60 & 2 & 3,5 & 3 & 3,3 & 3 & 3,3 \\
\hline Qualidade e quantidade de efluentes líquidos & 6 & 3,5 & 1,38 & 1 & 3,0 & 3 & 3,0 & 2 & 4,5 \\
\hline Redução de desperdícios & 9 & 3,6 & 0,73 & 2 & 3,0 & 4 & 3,5 & 3 & 4,0 \\
\hline Redução de multas & 8 & 3,6 & 1,30 & 2 & 3,5 & 3 & 3,3 & 3 & 4,0 \\
\hline Melhoria da qualidade das emissões & 9 & 3,8 & 0,83 & 2 & 3,5 & 4 & 3,8 & 3 & 4,0 \\
\hline Adequação à legislação & 9 & 4,1 & 1,45 & 2 & 4,0 & 4 & 4,0 & 3 & 4,3 \\
\hline
\end{tabular}

Escala de 1 a 5 ( 1 = muito pouco; 2 = pouco; 3 = médio; 4 = muito; e 5 = muitíssimo); e nr: número de respondentes/ $\mu=$ média. 
restantes investem em controles de emissões (líquidas, atmosféricas e sólidas). Por outro lado, a manutenção de um SGA é citada por quatro empresas, sendo uma de médio porte (que possui ISO 14001) e três de grande porte (duas certificadas com ISO 14001). Uma das áreas de investimento exclusivo das grandes empresas é a de controle de ruído.

Uma outra questão levantada na pesquisa foi a motivação para os investimentos ambientais. Destaca-se o atendimento à legislação como a principal razão dos investimentos. Em uma questão de múltipla escolha, respondida por onze empresas, esse motivo é citado por nove delas. Para duas pequenas empresas respondentes, assim como para duas empresas de grande porte, esse é o único motivo. Para as demais, grandes e médias, há motivos concorrentes à legislação, como projetos internos espontâneos e atendimento aos objetivos e metas da empresa.

Nenhuma empresa realizou investimentos ambientais pressionados pelos clientes. Perguntados sobre o percentual de investimento em meio ambiente sobre o seu faturamento, apenas treze empresas responderam. Oito empresas indicam que normalmente aplicam de 0 a $1 \%$ do faturamento, outras cinco entre 1 e $2 \%$, sendo esses valores constantes nos anos de 2004 e 2005.

No que tange aos recursos humanos foi analisada a implantação de um programa de educação ambiental. Através de uma pergunta de múltipla escolha levantou-se que quatro empresas confirmaram a sua inexistência e oito afirmaram ter um programa informal. Apenas duas empresas de grande porte possuem um programa de educação ambiental formalizado sobre os princípios dos 3R (Redução, Reutilização e Reciclar), quatro focam em conservação de insumos (sempre por meio de palestras) e oito afirmam que eventualmente realizam palestras sobre o tema.

Dentre as nove empresas que avaliaram a intensidade dos impactos dos programas de educação ambiental sobre a competitividade da empresa (Tabela 7) há uma percepção positiva. As empresas vêem que a educação ambiental possibilita ganho de produtividade, redução de custos e melhoria de imagem. O aumento da produtividade é percebido principalmente em empresas de médio e grande porte. A certificação ISO 14001 é vista na avaliação geral com uma média centrada e um desvio padrão muito alto. Este desvio ocorre porque as quatro empresas respondentes se agruparam claramente em lados opostos. Duas empresas certificadas vêem a educação ambiental como importante aliada no processo de certificação, enquanto que as outras duas empresas não certificadas não valorizam esse item.

Verificou-se que oito das 16 empresas entrevistadas não possuem e nem planejam implementar um Sistema de Gestão Ambiental (SGA). As empresas sem um SGA são: três de pequeno porte, três de médio porte e duas grandes. Por outro lado, duas empresas de grande porte e uma de médio possuem SGA certificados pela ISO 14001. Outras três empresas possuem sistemas de gestão ambiental próprios (também duas de grande porte e uma de médio porte). Duas empresas (uma de médio e outra de grande porte) estão em processo de implantação. Estes resultados indicam uma relação entre o porte da empresa e a implementação do SGA, ou seja, as pressões são mais direcionadas para as empresas de grande e médio porte.

$\mathrm{O}$ atendimento à legislação foi o principal motivo apontado pelas seis empresas que implementaram um SGA. As empresas afirmam que as exigências legais são mais facilmente atendidas através do SGA. Em seguida, as empresas apontaram a melhoria na imagem, o avanço dos concorrentes e o atendimento às exigências dos clientes no exterior. Uma empresa implantou o SGA por exigência da matriz e outra empresa atendeu às reclamações da comunidade do entorno. Os benefícios decorrentes da implantação do SGA estão apresentados na Tabela 8. Cinco empresas responderam a melhoria da imagem e outras perceberam benefícios operacionais, tais como: controle de processo e redução de custos. Os benefícios são percebidos principalmente pelas empresas de grande porte.

A pesquisa identificou que somente as empresas certificadas com ISO 14001 (três de grande porte) fazem exigências contratuais aos seus fornecedores e recebem exigências dos seus clientes. Estas exigências envolvem a norma ISO 14001, selo verde ou um padrão próprio.

Dois indicadores que contribuem para a avaliação da conduta ambiental são: a existência de um plano de

Tabela 7. Impacto do programa de educação ambiental na competitividade.

\begin{tabular}{|c|c|c|c|c|c|c|c|c|c|}
\hline \multirow[b]{3}{*}{ Indicadores } & \multicolumn{3}{|c|}{ Avaliação geral } & \multicolumn{6}{|c|}{ Avaliação por porte } \\
\hline & \multirow[b]{2}{*}{$\mathbf{n r}$} & \multirow[b]{2}{*}{$\mu$} & \multirow[b]{2}{*}{ Desvio padrão $\sigma$} & \multicolumn{2}{|c|}{ Pequena } & \multicolumn{2}{|c|}{ Média } & \multicolumn{2}{|c|}{ Grande } \\
\hline & & & & $\mathbf{n r}$ & $\mu$ & $\mathbf{n r}$ & $\mu$ & nr & $\mu$ \\
\hline Certificação ISO 14001 & 4 & 3,0 & 2,31 & 0 & - & 1 & 5,0 & 3 & 2,3 \\
\hline Aumento da produtividade & 9 & 3,7 & 0,87 & 1 & 3,0 & 5 & 3,6 & 3 & 4,0 \\
\hline Redução de custos & 9 & 3,3 & 0,71 & 1 & 3,0 & 5 & 3,4 & 3 & 3,3 \\
\hline Melhoria da imagem & 8 & 3,4 & 1,06 & 1 & 3,0 & 4 & 3,8 & 3 & 3,0 \\
\hline
\end{tabular}

Escala de 1 a 5 ( $1=$ muito pouco; $2=$ pouco; $3=$ médio; $4=$ muito e 5 = muitíssimo); e nr: número de respondentes $/ \mu=$ média. 
Tabela 8. Benefícios percebidos com a implementação do SGA.

\begin{tabular}{|c|c|c|c|c|c|c|c|c|c|}
\hline \multirow[b]{3}{*}{ Indicadores } & \multicolumn{3}{|c|}{ Avaliação geral } & \multicolumn{6}{|c|}{ Avaliação por porte } \\
\hline & \multirow[b]{2}{*}{ nr } & \multirow[b]{2}{*}{$\mu$} & \multirow[b]{2}{*}{ Desvio padrão $\sigma$} & \multicolumn{2}{|c|}{ Pequena } & \multicolumn{2}{|c|}{ Média } & \multicolumn{2}{|c|}{ Grande } \\
\hline & & & & $\mathbf{n r}$ & $\mu$ & nr & $\mu$ & nr & $\mu$ \\
\hline Maior controle do processo & 4 & 4,5 & 0,58 & 0 & - & 1 & 4 & 3 & 4,7 \\
\hline Redução dos custos & 4 & 4,0 & 0,82 & 0 & - & 1 & 4 & 3 & 4,0 \\
\hline Melhoria da imagem & 4 & 4,0 & 0,82 & 0 & - & 1 & 4 & 3 & 4,0 \\
\hline Aumento das vendas no mercado externo & 3 & 2,7 & 0,58 & 0 & - & 1 & 2 & 2 & 3,0 \\
\hline Aumento das vendas no mercado nacional & 3 & 1,7 & 0,58 & 0 & - & 1 & 2 & 2 & 1,5 \\
\hline Redução de multas/autuações & 2 & 1,5 & 0,71 & 0 & - & 0 & - & 2 & 1,5 \\
\hline
\end{tabular}

Escala de 1 a 5 (1= muito pouco; 2 = pouco; 3 = médio; 4 = muito; e 5 = muitíssimo); e nr: número de respondentes/ $\mu=$ média.

resposta a situações de emergência e a realização de auditorias ambientais. Observa-se que sete, de treze respondentes, realizam auditorias ambientais, e onze empresas têm um plano de atendimento a emergências. Os resultados indicam que há uma possível relação com o porte, ou seja, pequenas empresas não realizam as auditorias ambientais.

Analisando os indicadores de conduta ambiental das empresas têxteis entrevistadas, se observa que quatro empresas adotam os perfis de conduta forte, quatro empresas possuem uma conduta intermediária e oito revelam uma conduta fraca (Tabela 9).

Fazendo uma análise por porte da conduta ambiental, se observa que todas as pequenas empresas adotam uma conduta fraca, e as empresas de médio porte também se concentram nos perfis de conduta fraca (três empresas). Entretanto, duas empresas de médio porte adotam uma conduta intermediária e apenas uma empresa apresenta-se com conduta forte. Por outro lado, as grandes empresas concentram-se nos perfis de conduta ambiental forte (três empresas), duas possuem condutas intermediárias, contudo, duas empresas adotam uma conduta fraca.

Os resultados da pesquisa permitem inferir que existe uma maior preocupação com a conduta ambiental que a conduta social. Este comportamento decorre da existência de pressões ambientais da estrutura da indústria, principalmente provocadas por clientes e comunidade, além das exigências legais. A pesquisa revelou que essas pressões são mais fortes e presentes na área ambiental que social.

\section{Perfis sociais e ambientais das empresas têxteis}

O cruzamento das Tabelas 4 e 9 permite levantar o perfil estratégico de conduta social e ambiental da indústria têxtil nordestina. As 16 empresas foram identificadas com uma letra (relativa ao porte) e um dígito. Sendo assim, as três empresas de pequeno porte foram designadas como P1, P2 e P3; as seis empresas de médio porte
Tabela 9. Avaliação do perfil de conduta ambiental.

\begin{tabular}{lcccc}
\hline & & \multicolumn{3}{c}{ Freqüiência por porte } \\
\cline { 3 - 5 } Perfis de conduta ambiental & nr & Pequena & Média & Grande \\
\hline Conduta fraca & 8 & 3 & 3 & 2 \\
Conduta intermediária & 4 & - & 2 & 2 \\
Conduta forte & 4 & - & 1 & 3 \\
\hline
\end{tabular}

nr: número de respondentes.

foram denominadas de M1, M2, M3, M4, M5 e M6; e as sete empresas de grande porte foram nomeadas de G1 até $\mathrm{G} 7$

O Quadro 2 permite visualizar a correlação entre as condutas ambientais e sociais e o porte das empresas pesquisadas. Observa-se um maior agrupamento de empresas que possuem condutas ambientais e sociais fracas. As empresas de pequeno porte estão concentradas nas condutas fracas e apenas uma empresa adota uma conduta ambiental fraca e conduta social intermediária. Das seis empresas que possuem condutas duplamente fracas, apenas uma delas é de grande porte.

A pesquisa evidencia que a questão ambiental não é um desdobramento da questão social. A conduta ambiental forte ou intermediária é praticada por metade das empresas entrevistadas. Por outro lado, a conduta social concentra-se nos perfis intermediários e fracos revelando dez empresas com conduta social fraca. Observa-se que duas empresas (M1 e G5) com conduta social fraca possuem conduta ambiental forte e outras duas empresas que adotam uma conduta ambiental intermediária (M6 e G6) também possuem uma conduta social fraca.

Por outro lado, somente duas empresas com uma conduta social intermediária (P1 e M4) agem fracamente em relação às questões ambientais. As últimas quatro empresas citadas no quadro - G2, G3, G4 e G7 - confirmam a hipótese da relação entre o porte com a conduta ambiental, ou seja, à medida que aumenta o porte das empresas existe uma tendência de adoção de um posicionamento estratégico mais responsável. 
Quadro 2. Correlação dos perfis de conduta ambiental e social com o porte.

\begin{tabular}{lccc} 
& \multicolumn{3}{c}{ Conduta ambiental } \\
\cline { 2 - 4 } \multicolumn{1}{c}{ Conduta social } & Fraca & Intermediária & Forte \\
\hline Fraca & $\mathrm{P} 2, \mathrm{P} 3, \mathrm{M} 2, \mathrm{M} 3, \mathrm{M} 5, \mathrm{G} 1$, & $\mathrm{M} 1, \mathrm{G} 5$ \\
Intermediária & $\mathrm{P} 1, \mathrm{M} 4$ & $\mathrm{G} 7$ & $\mathrm{G} 3$ \\
Forte & & $\mathrm{G} 4$ & $\mathrm{G} 2$ \\
\hline
\end{tabular}

\section{Conclusão}

Tomando como ponto de partida o paradigma SCP, o artigo apresentou o modelo de avaliação da estratégia tríplice (ECP-triplo) como uma proposta metodológica que responde à necessidade de readequação do "tripé da sustentabilidade empresarial", pensando não apenas na variável econômica como influenciadora na competitividade, mas também nas dimensões ambiental e social. $\mathrm{O}$ uso do modelo ECP-triplo contribui para que as empresas avaliem, de forma simples, as condutas sociais e ambientais e definam qual o perfil que desejam ocupar.

O questionário construído conforme os indicadores propostos no framework do ECP-triplo, abrangendo perguntas de estrutura, conduta e performance, permitiu coletar dados de uma amostra representativa (sobre a produção) da indústria têxtil nordestina. $\mathrm{O}$ artigo analisou as condutas sociais e ambientais e as classificou conforme perfis de conduta, dentro de uma escala de fraca, intermediária e forte, permitindo inferir o comportamento da indústria.

Os perfis de conduta forte concentram-se nas empresas de grande porte. Esta relação entre a conduta e o porte das empresas fica mais explícita na conduta ambiental. Aumentando o porte ocorre um incremento no risco ambiental, uma maior exposição à sociedade e por fim um controle mais rígido dos órgãos reguladores. $\mathrm{O}$ estudo sugere que as empresas de grande porte, com participação em mercados internacionais diferenciados, estão submetidas a exigências ambientais além das legais (i.e., como a certificação ISO 14001). Resultados semelhantes foram encontrados por Christmann e Taylor (2001), que identificaram uma correlação positiva entre o tamanho da empresa e as práticas de gestão ambiental em empresas chinesas que exportam para países desenvolvidos.

A ausência de exigências sociais, além do atendimento aos requisitos trabalhistas, pode explicar a relação mais fraca entre o porte e a conduta social - dentro de um panorama geral de condutas fracas. Sem pressões das partes interessadas internacionais (clientes) e num cenário local onde a criação de empregos e o cumprimento da legislação são considerados uma ação social suficiente, a conduta da indústria têxtil nordestina tende a ficar no nível mais fraco, i.e., atuando na base da pirâmide de responsabilidade social nas categorias econômica e legal, proposta por Carrol (1991).

A pesquisa revelou que não é possível simplificar o tripé econômico-social-ambiental, proposto por Elkington (1998), para análise de resultados de corporações - em um simples par econômico e "socioambiental", visto que há pressões externas distintas nas áreas ambientais e sociais.

Limitações nesta pesquisa devem ser reconhecidas. A primeira inclui o número de firmas entrevistadas. A generalização, portanto, para toda indústria têxtil nordestina exigirá uma investigação mais ampla. A segunda limitação envolve um estudo estático, ou seja, não é possível capturar mudanças nas pressões e condutas ao longo do tempo. Neste ponto sugere-se que estudos periódicos sejam conduzidos para identificar as mudanças nas estratégias sociais e ambientais. Esta pesquisa abre, portanto, uma agenda para novos aprofundamentos analíticos, utilizando o modelo ECP-triplo como orientação metodológica na tomada de decisão estratégica das empresas dentro de um mercado globalizado e competitivo. 


\title{
Social and environmental strategic conduct profile: studies of Northeast Brazil textile industry
}

\begin{abstract}
This paper presents a social and environmental behaviour assessment of Northeast Brazil textile industry using the strategic assessment framework, named the triple-SCP model. This model is an expansion of the structure-conductperformance paradigm adding the assumption that the triple performance (economic, environmental and social) of a company is the result of its competitive practices or conduct standards, depending on the industrial structure in which it operates. The data were collected from textile companies located in Ceará, Paraíba, Pernambuco and Rio Grande do Norte states through in-depth personal interviews. The study categorized companies by size and identified social and environmental strategic conduct profiles. The conduct of the companies was rated as strong, medium or weak. The results show that most of firms adopt weak conduct on both social and environmental matters. Overall companies are more concerned about environmental issues than social ones. In general, larger firms and those which have international markets tend to have a stronger environmental and social conduct.
\end{abstract}

Keywords: SCP-triple model. Environmental management sustainability. Socio indicators. Environmental indicators. Textile industry.

\section{Referências bibliográficas}

ABREU, M.C.S. Modelo de Avaliação da Estratégia Ambiental: Uma Ferramenta para Tomada de Decisão. Florianópolis, 2001. 218p. Tese (Doutorado em Engenharia de Produção) Programa de Pós-Graduação em Engenharia de Produção, Universidade Federal de Santa Catarina - UFSC.

ABREU, M.C.S.; FIGUEIRÊDO Jr., H.S.; VARVAKIS, G. Modelo de Avaliação da Estratégia Ambiental: Os Perfis de Conduta Estratégica. Gestão Ambiental e Competitividade na Empresa, READ Edição Especial 30, Porto Alegre, v.8, n.6, dez. 2002.

ANÁLISE SETORIAL: FIAÇÃO, TECELAGEM, MALHARIA. Gazeta Mercantil S.A., São Paulo, 1999. (Panorama Setorial, V. I).

ANÁLISE SETORIAL: FIAÇÃO, TECELAGEM, MALHARIA. Gazeta Mercantil S.A., São Paulo, 1999. (Panorama Setorial, V. II).

BANCO DO NORDESTE. O Segmento da Malharia da Indústria Têxtil do Nordeste. Estudos Setoriais, Fortaleza, n.6, p.74, 1999.

BAIN, J.S. Barriers to New Competition. Cambridge: Harvard University Press, 1956. 339p.

BOCKERMANN,A.; MEYER, B.; OMANN, I.; SPANGENBERG, J. H. Modelling Sustainability. Comparing an Econometric (PANTA RHEI) and a Systems Dynamics Model (SuE). Journal of Policy Modeling, v. 27, p.189-210, 2005.

BRAILE, P.M.; CAVALCANTI, J.E.W.A. Manual de Tratamento de Águas Residuárias Industriais. São Paulo: CETESB,1993. $764 \mathrm{p}$.

CARROLL, A.B. A Three Dimensional Conceptual Model of Corporate Performance. Academy Management Reviews, v.4, n.4, p. 497-505, 1979.

CARROLL, A.B. The Pyramid of Corporate Social Responsibility: Toward the Moral Management of Organizational. Business Horizon, v.4, jul-ago, p.39-48, 1991.
COEMA. Conselho Estadual do Meio Ambiente (do Estado do Ceará). Resolução COEMA No. 08, de 15 de Abril de 2004. Disponível em: <http://www.semace.ce.gov.br/biblioteca/ legislaCAO/ResolCOEMA08-04.pdf>. Acesso em: 09 jan.2007.

CHRISTMANN, P.; TAYLOR, G. Globalization and the Environment: Determinant of Firm Self-regulation in China. Journal of International Business Studies, v.32, n.3, p.439-458, 2001.

DEMSETZ, H. Industry Structure, Market Rivalry, and Public Policy. Journal of Law and Economics, v.16, p.1-9, 1973.

ELKIngton, J. Cannibals with Forks: The Triple Bottom Line of 21st Century Business. Canadá: NSP, 1998. 229 p.

ELKINGTON, J. Triple Bottom Line Revolution: Reposting for the Third Millennium. Australian CPA, v.69, p. 75-77, nov. 1999.

ELKINGTON, J., TRISOGLIO, A. Developing Realistic Scenarios for Environment: Lessons from Brent Spar. Long Range Planning, v.29, n.6, p 762-769, 1996.

INSTITUTO ETHOS de Empresas e Responsabilidade Social. Indicadores Ethos de Responsabilidade Social. São Paulo: Instituto Ethos de Empresas e Responsabilidade Social, 2000.

McWILlIAMS, A.; SMART, D.L. Efficiency v. StructureConduct-Performance: Implications for Strategy Research and Practice. Journal of Management, v.19, p.63-78, 1993.

NORCIA, V. Environmental and Social Performance. Journal of Business Ethics, v.15, n. 7, p. 773-784, 1996.

OECD. Organization for Economic Co-Operation andDevelopment. Towards Sustainable Development: Environmental Indicators. Paris: OECD, 1998. 132 p.

KUNZ, A.; PERALTA-ZAMORA, P.G. Novas Tendências no Tratamento de Efluentes Têxteis. Química Nova, v.25, p.78, 2002.

PORTER, M. E. Competitive Strategy. New York: The Free Press, 1980. 396 p. 
SAI. Social Accountability International. RESPONSABILIDADE SOCIAL 8000 (SA 8000). New York, USA: SAI, 2001. (tradução Granville Traduções). 11 p.

RUMELT, R.P. How much does Industry Matter? Strategic Management Journal, v.12, p.167-185, 1991.

RYE, H.; CELIUS, H.; HUSDAL, G.; GUTTORMSEN, R. Environmental Indicators Applied to the Norwegian Oil and Gas Industry. SPE/UJKOOA European Environmental Conference, Aberdeen, 15 - 16 abr., 1997. Society Petroleum Engineers, Paper No. 37849, 1997.
SCHERER, F. M.; ROSS, D. Industrial Market Structure and Economic Performance. 3. ed. Boston: Houghton Mifflin, 1990. 713 p.

UNE, M.; PROCHNIK, V. Oportunidades de Investimento na Cadeia Têxtil Nordestina. In: HAGUENAUER, L. PROCHNIK, V. Identificação de Cadeias Produtivas e Oportunidades de Investimentos no Nordeste. Fortaleza: Banco do Nordeste, 2000. 394 p.

\section{Sobre os autores}

\section{Mônica Cavalcanti Sá de Abreu \\ José Carlos Lázaro da Silva Filho \\ Bruno Cals de Oliveira \\ Francisco Leite Holanda Júnior}

Laboratório de Estudos em Competitividade e Sustentabilidade - LECoS,

Departamento de Administração, Universidade Federal do Ceará - UFC,

Av. da Universidade, 2470, CEP 60020-180 Benfica, Fortaleza, CE, Brasil,

e-mail: mabreu@ufc.br; silva.filho@pq.cnpq.br; brunocalsadm@yahoo.com.br; holanda_jr@hotmail.com

Agradecimentos: ao CNPq pelo apoio financeiro ao projeto de pesquisa; aos Sindicatos Patronais das Indústrias Têxteis pelo apoio institucional; às empresas pesquisadas, por nos confiarem seu tempo e informações valiosas; e aos revisores por suas sugestões e comentários. 